\title{
Crime among young Moroccan men in the Netherlands: Does their regional origin matter?
}

European Journal of Criminology

(C) The Author(s) 2015

Reprints and permissions: sagepub.co.uk/journalsPermissions.nav DOI: I0.1 I77//4773708I5623566 euc.sagepub.com

@SAGE

\author{
Frank Bovenkerk \\ University of Utrecht, The Netherlands
}

\section{Tineke Fokkema}

Netherlands Interdisciplinary Demographic Institute (NIDI-KNAW), University of Groningen, The Netherlands; Erasmus University Rotterdam, The Netherlands

\begin{abstract}
High crime rates among second-generation immigrants are usually attributed to the ethnic group's weak socioeconomic position in the host society. The causes of crime can, however, also be sought in their native countries or regions. Owing to a lack of empirical data, this has rarely been tested. The Netherlands is an exception: small-scale ethnographic case studies among young Moroccan men in Dutch cities suggest that their regional background and culture, particularly if they are from the less developed Rif Mountains area, may explain their high crime rates. In this article we examine whether this applies to the results of a quantitative study on all the Moroccan male juveniles in the Netherlands. At the individual level, our unique dataset is a combination of their native regions, criminal records (ever suspected of a crime) and demographic and socioeconomic characteristics. Logistic regression analysis shows that current socioeconomic position is a strong predictor of ever having been suspected of a criminal offence, and the impact of geographical descent, directly or indirectly via socioeconomic position in the Netherlands, is negligible. Accordingly, our findings on Moroccans in the Netherlands do not warrant our questioning the common explanation of the immigrant-crime connection in criminology and suggest further research to determine the specific host society's features that explain the overrepresentation of ethnic groups in crime statistics.
\end{abstract}

\section{Keywords}

Immigrant-crime connection, integration, Morocco, second-generation immigrant crime

\section{Corresponding author:}

Frank Bovenkerk, Willem Pompe Institute, University Utrecht, Boothstraat 6, Utrecht, 35I2BW, The

Netherlands.

Email: F.Bovenkerk@uu.nl 


\section{Introduction}

It has now been 50 years since the first Moroccan men came to the Netherlands as guest workers or labour migrants. Especially after the oil crisis of 1973 and the economic recession of the early 1980s, approximately half of them had their families come as well, starting with the Moroccan immigrant community, which, according to Statistics Netherlands, now (1 January 2014) consists of 374,694 people. A first generation, a 1.5 generation that grew up partly in Morocco and then in the Netherlands, and a second generation of Moroccan-Dutch persons can now be distinguished. Although the majority have Dutch or dual citizenship (Loozen et al., 2012: 37), it is still common practice in the Netherlands to label all generations as Moroccans. About two-thirds come from (a) the Rif Mountains region along the north coast, (b) the south in the area around Agadir (Souss) and Ouarzazate, and (c) the cities of Tangiers, Casablanca, Fes, Meknes, Marrakech and Rabat. In the Netherlands, most Moroccans live in the four large cities of the Randstad conurbation: Amsterdam, Rotterdam, The Hague and Utrecht (Fokkema et al., 2009).

Ever since the early 1990s, young men from this group are believed to have posed a persistent crime problem that not only includes disturbing the peace and vandalism but also high-impact offences such as mugging, burglary and armed robbery. More than half the 1.5 and second generation of young Moroccan men have been charged by the police with one or more criminal offences of varying severity by the time they are 23 (Blokland et al., 2010). Figures in the 2011 Integration Report of the Netherlands Institute for Social Research (Van Noije and Kessels, 2012: 207) are as high as 65 percent - striking because the first generation of immigrants had a below-average crime rate.

It initially seemed as if the high figures could be explained by an overrepresentation of young Moroccan men in the lower socioeconomic segments of society. But, as far back as 1990, Junger noted on the basis of self-reported data that Moroccan crime rates for this age group are significantly higher than the average in the lowest socioeconomic segments of society and those of other minorities. Based on Dutch Police Department suspect figures (HKS: Herkenningsdienstsysteem, Police Identification Service System) for 2009, researchers at the Netherlands Institute for Social Research calculated the extent to which general risk factors (sex, age, educational level, income, urbanization) determine the level of overrepresentation of various groups of non-Western youths. It was lowest in the case of Moroccans (Van Noije and Kessels, 2012: 214-5). A second plausible explanation is that Moroccans' overrepresentation in crime statistics is the result of selective policing and discrimination. Recently there has been a heated discussion on the issue of ethnic profiling by the Dutch police. The results of empirical research are not conclusive so far (Bovenkerk, 2014; Cankaya, 2012; Svensson and Saharso, 2014). However, as Junger-Tas argued about the exceptional rise of Moroccan crime rates that began to appear in the 1990s: 'Even if the police is prejudiced this would not explain the disparities in crime rates between various minorities. Why would the police discriminate Moroccans more than other ethnic groups?' (Junger-Tas, 1997: 283).

Dutch ethnic studies researchers often make references to Moroccans' regional background and culture. High delinquency rates are assumed to be the result of (1) the primitive conditions in the rural regions most of the immigrants come from and (2) the Berber 
culture of the Rif Mountains in the north, with its resistance towards the central government, where approximately two-thirds of them are from. Such notions are based mainly upon small-scale ethnographic fieldwork among groups of problematic young Moroccan men in large Dutch cities (Van Gemert, 1998; Werdmölder, 1997), pedagogical research on Moroccan families and psychological studies of individual criminals in the Netherlands (Brons et al., 2008). How do such insights fit into the theories on crime and immigration, and - this is the core of this article - do they stand up to a quantitative test: to what extent can differences in crime rates among young Moroccan men be attributed to their regional descent? This question is answered by comparing the Dutch criminal records (ever suspected of a crime) of young Moroccan men who have a background in the countryside respectively the Rif with those who originate in cities respectively other parts of Morocco.

\section{Immigration and crime}

Concerns about crime among immigrants have a long history and have often been fed by anti-immigration and xenophobic sentiments. Newcomers were thought to compete unfairly in the labour market, deplete welfare resources, cause housing shortages and create other social problems. However, assumptions that the crime rates of first-generation immigrants are higher than average have been consistently contradicted by scientific research that shows lower crime rates instead. Such findings on immigrant crime in 1920s USA by Chicago sociologists (Park et al., 1967) were confirmed in Europe by Ferracuti, who wrote a comprehensive work on the topic in 1968. In 1996, Yeager once again corroborated this 'general rule' in a meta-analysis that also included experiences in Canada and Australia. For violent crime, Robert J. Sampson has shown that, in the USA, 'cities of concentrated immigration are some of the safest places around' (Sampson, 2008: 30). These findings have served as an important argument against those wanting to stop immigration on the grounds of fear. But it was also noted that immigrants 'import' their countries' crime traditions to a certain extent. For example, first-generation southern Italians were relatively likely to commit homicides and Finns more apt to commit crimes directly related to excessive drinking (Sutherland, 1939: 125). Moreover, the crime rates for many second-generation immigrants born in the new land were found to be higher than average for their age group, and rates for the 1.5 generation of immigrant boys (with a cut-off generally set at an immigration age of 12; Rumbaut, 2004) lie somewhere in between.

\section{Host country influences}

In the past two decades, empirical study of the possible link between immigration and crime has been in full swing (Bucerius and Tonry, 2014; Marshall-Haen, 1997; Solivetti, 2010; Tonry, 1997), and second-generation immigrant crime has become a topic of scientific interest on its own right (Waters, 1999). So far, most sociological studies in search of the causes of an immigrant crime problem have confined themselves to analysing data on the social, economic and cultural developments of immigrant groups in the host country. The theories of social integration and acculturation roughly predict that, in the long run, crime among successive generations of immigrants will come to resemble the crime 
rate and profile of society at large (Junger-Tas, 2001). The level of delinquency of each immigrant community will vary according to the levels of structural and cultural integration of the group. This viewpoint does not account for the specific crime problems of the first and 1.5 generations, and the second-generation crime problem needs a more refined explanation. At least three other strands of sociological theory that address the secondgeneration crime problem in particular - social disorganization, cultural dissonance and strain theory - with roots in sociology work of 1920s Chicago, satisfy this need and in the process inspire contemporary empirical study on the subject (Simes and Waters, 2014: 460-1; Thomas, 2011).

Social disorganization theory (Shaw and McKay, 1942) argues that an absence of social cohesion and normative consensus leads to crime. This theory has served to explain the patterns of high crime rates in areas that Chicagoans called zones of transition - poor city neighbourhoods where immigrant children grew up under conditions of economic deprivation, physical deterioration and high resident turnover. The heterogeneity and transience of the population in these areas made it particularly difficult to organize the neighbourhood and supervise children. At the same time, Chicagoans did see that some groups exhibited greater social disorganization than others, even if their socioeconomic status was the same. The Chicago researchers explained this by noting that groups could escape from disorganization by preserving their social cohesion or forming a 'colony' or 'ghetto' (Park et al., 1967: 107). Aronowitz (2002) uses this notion in order to explain the effectiveness of social control of juvenile delinquents in the Turkish community of Berlin today. Within their own circle in Germany, for a while, people were able to preserve their traditional mechanisms of social control. She finds that crime rates among the second generation born in Germany are higher than those of youngsters who were born and educated in Turkey and brought to Berlin as children (what we call the 1.5 generation).

A second line of theory-building would later be called relative deprivation or strain theory (Merton, 1949). Strain theorists of Chicago argued that the parents' generation was satisfied with simple jobs and a low income in the host country because they compared them with the economic and political conditions in their native country. However, the second generation compared themselves at school and on the street with Americans and had higher material demands, which led to strain and possibly to crime. We have found no references to the 1.5 generation among strain theorists.

The theory of cultural conflict or cultural dissonance (Sellin, 1938) focuses on the immigrant experience of people being thrust into a milieu in which cultures and 'conduct norms' clash, particularly when rural immigrants find themselves in a cosmopolitan city setting. The first generation of immigrants may live in the culture in which they were brought up in the country of origin. The second generation suffers most from the conflict of cultures. Children of immigrants are vulnerable when they find themselves in the noman's land between two cultures. They may not have been able either to internalize the culture of their parents or to integrate into the new society. The 1.5 generation takes an intermediate position. Shoham (1962: 212) specified this theory by pointing at the possibility that the economic status of the head of the family will often be 'injured' in the process of integration. This leaves youngsters in a state of confusion that pushes them into the 'street culture' to become juvenile delinquents. 


\section{Effects of the country of origin}

Surprisingly, none of these three theories has paid explicit attention to the specific social, cultural or political backgrounds the immigrants had in their country of origin. The link between immigrants' origin and crime in the theory of social disorganization is indirect and unspecified: the mere fact that immigrants settle in poor neighbourhoods that are in a continuous state of demographic flux results in social disorganization. This in turn increases the crime rate. The motor of criminality in strain theory lies in the attraction of the 'success goals' of affluent US society and the lack of legitimate means to attain them. A lack of education or experience working in modern industrial conditions absent in the country of origin are not explicitly taken into account. Cultural conflict theory looks for differences in norms and values but does not involve a full examination of the cultural and economic geography of the country of origin. This neglect of interest in the country of immigrant origins also holds true for the deviant street subcultures that have developed among the second generation. Take, for example, the famous ethnography by William Foote Whyte's Street Corner Society (1943) in Boston. The fact that the parents of the Corner boys were of Italian descent (more precisely, they came from the hills of Avellino near Naples) is almost completely ignored. ${ }^{1}$

Probably as a consequence, criminologists and other social scientists have rarely looked at the country of origin. More recently, however, an increasing recognition of the role of the home country is noticeable. In his theoretical frameworks for theory and research about the immigrant-crime nexus, Mears encourages us explicitly to take background variables in the country of emigration and subpopulations within the immigrant flow into account (Mears, 2001:10). Thomas finds a delinquent's background relevant because immigrants enter the new country with 'tremendously varied experiences in their home countries, communities, family, and friendship networks' (Thomas, 2011: 384).

Dutch researchers are an exception in this respect. In the Dutch tradition of cultural geography and ethnography, researchers have long included immigrants' backgrounds when describing and analysing their social problems. They have conducted fieldwork in the countries of emigration (for example, Suriname, the Netherlands Antilles, Turkey, Morocco), and more precisely in the regions from which immigrants predominantly have come (Van Amersfoort, 1982). In Morocco, they studied the varying levels of social capital among the sending population (De Mas, 1987) and the family history of the emigrants (Van den Berg-Eldering, 1978). From the moment that Dutch social scientists began studying crime and delinquency among immigrant groups (around 1990), they explicitly included in their analyses variables pertaining to conditions in the countries of origin (for example, Van Gemert, 1998, and Werdmölder, 1997, in Morocco).

In the years of Moroccan family reunification in the Netherlands, Dutch researchers discussed the possible causes of crime problems in the 1.5 generation. Did the criminality of young migrants start before the move or after they settled in the Netherlands? Werdmölder (1997) and Van den Berg-Eldering (1978) show that youngsters who arrived in the Netherlands as the 1.5 generation were already engaged in criminal activities or juvenile delinquency in Morocco. This has to do with the Moroccan way of bringing up children, especially in the Berber region of the Rif. Young children are brought up by their mother, but, starting at the age of 8 , the father 
is responsible. Boys become part of the men's world and spend a lot of time outside the home. They spend time at school, on the street and at the market. When their fathers are in Europe, there is no one to discipline and correct them. For mothers, the risk of losing their grip on their sons and having them 'go bad' was an important reason to insist on family reunification in Europe. Social control, to the extent that it still existed in Morocco, decreased further in the Netherlands.

More in general, Moroccan crime in the Netherlands is often explained by the fact that most of these immigrants originate from an underdeveloped countryside and from the northern Rif area, which has a reputation for 'rough individualism' and political rebelliousness. Dutch researchers' descriptions of the major regions of Moroccans' provenance have found their way to a larger public, and their argument that Moroccans' overrepresentation in crime statistics is attributable to the specificities of these regions is now considered as 'social fact' that is disseminated in universities and in special courses on minorities for law enforcement personnel. Specialists comment in the media on conspicuous incidents of crime that involve people with an immigration background from the north of Morocco. The theme is often discussed among 'Moroccan' intellectuals in the Netherlands (for example, in the novel Bad Boy by Abdelkader Benali). Police officers, attorneys and local authorities make 'discovery trips' to the Rif area in order to gain insight into the background of the problem.

\section{Expected differences in Moroccan crime by regional origin}

The 'social fact' that the rural and Rif background of the majority of Moroccan immigrants to the Netherlands is largely responsible for their high crime rates implicitly or explicitly assumes differences in crime rates by regional descent. The assumption goes that, if the migration from Morocco to the Netherlands were less selective, with more people from cities and modern regions than the Rif area, there would be less of a Moroccan crime problem. Although there are plausible arguments for this notion, to our knowledge it has never been directly studied or quantitatively tested prior to this study.

Rural versus urban. Given the sociological theories of immigration described above, it is only logical to assume that, the more the native region and host country differ socioeconomically and in terms of modernity, the greater the gap and the longer it takes to integrate. For example, immigrants from a close-knit community in the poor countryside who have not had much education have more trouble transitioning to an anonymous urban environment than well-educated urbanites. Eisenstadt followed this line of reasoning when he explained the high crime rates among Sephardic Jews (Moroccans!) in Israel as follows: 'The disorganisation of the immigrant group, instability of social relations, and of various types of norm-breaking, juvenile delinquency, crime etc. is strongest among those groups whose cultural and educational standards are much lower than those of the absorbing society' (Eisenstadt, 1954: 261). Similarly, Junger-Tas (1997: 300-1), who has been the advocate of integration theory in the Netherlands, explains high crime rates among immigrant minorities through their weak socioeconomic position, which results from a considerable 'culture lag' with respect to the home country. She specified the cultural dimension of the conflict of cultures. There were differences between values 
such as traditionalism versus modernism, and respect for authority versus democratic decision-making (Junger-Tas, 2001: 23).

The conditions for explaining crime through differences in economic development and culture between the Moroccan countryside and urban Netherlands seem fulfilled. The socioeconomic and cultural distance from the Moroccan countryside to Dutch urban society is huge. Two-thirds of all immigrants came from rural areas, and here we include the smaller towns of Al Hoceima and Nador. Bouras (2012: 52) notes in her history of Moroccans in the Netherlands that people from the countryside had much larger families than those from the cities and had to make much more of a transition from their traditional lifestyle to settle in the Netherlands. The literature on Moroccan emigration gives examples of illiterate women who had their first experience with city life when they came to Europe and had a very hard time coping with modernity. How were they supposed to raise their children in this environment? Pels and De Haan (2007) write about parents facing child-rearing uncertainty. Moroccan fathers were also all too aware that the contrast between the old and new cultures could lead to behavioural problems on the part of their children. They could foresee that their children would be exposed to the 'depravity of the West', which is why they resisted the idea of family reunification for such a long time (Eldering, 1995).

If the socioeconomic and cultural distance is what determines how hard it is to bridge the gap, Moroccans from the countryside might be expected to be more likely to develop criminal behaviour than those from the cities. This would particularly hold for the second generation and, to a lesser extent, the 1.5 generation, given their higher likelihood of suffering from a conflict of cultures and their higher material demands. Accordingly, the following hypotheses can be formulated:

H1a. Crime rates in the Netherlands are higher among Moroccans who come from the countryside or whose parents do than among those who come from Moroccan cities or whose parents do.

H1b. The rural-urban difference in criminality is largest among the second generation and smallest among the first, with the 1.5 generation occupying an intermediate position.

H1c. The rural-urban difference in criminality decreases after correcting for differences in socioeconomic situation in the Netherlands.

Rif versus the rest. Apart from the rurality of the Rif Mountains, the level of development of this area has been notoriously low (De Mas, 1987). Using the concept of social capital, De Mas (1987) explains the contrast in regional mentality, entrepreneurship and extent of integration in the national state between the southern Souss and the northern Rif Mountains in Morocco. There are geographical and historical reasons why the Rif fell behind in the development process (De Mas, 2001). With its steep cliffs on the coasts, for those in power the Rif was always a buffer zone against invasions from the north instead of an integral part of the country. Until recently, the Rif was the poorest part of the country. Between 1912 and 1956, when Morocco was colonized by the French, the Rif was Spanish and remained underdeveloped. Its inhabitants speak one of the Berber languages, Spanish and Moroccan Arabic, but not French. The region was originally a tribal society, but was administered by Arab officials and not Berbers. After independence, King 
Hassan II developed a hostile relationship with his subjects in the region by violently suppressing the rebellions in 1958-9. In ethnography, the social structure of the Rif tribes is described as weak, and families distrust each other (Hart, 2000). There is hardly a level of social or political control above the level of individual families. When the father is absent because he is working overseas as a migrant worker, his sons grow up in relative freedom. This accounts for the deviance of the 1.5 generation. The second generation grows up in Europe, where the patriarch of the family has lost much of his control over his children. It is difficult to exert corrective social control over the younger generation in a group where social cohesion is low and where families distrust each other. The following hypotheses can be formulated:

H2a. Crime rates in the Netherlands are higher among Moroccans who are from the Rif or whose parents are than among those who are from elsewhere in Morocco or whose parents are.

H2b. The Rif-elsewhere difference in criminality is largest among the second generation and smallest among the first, with the 1.5 generation occupying an intermediate position.

H2c. The Rif-elsewhere difference in criminality decreases after correcting for differences in socioeconomic situation in the Netherlands.

\section{Research design: Data and methods}

\section{Data}

The analyses were conducted using data from the System of Social Statistical Datasets (SSD) at Statistics Netherlands, which contains data on virtually the entire population of the Netherlands in a system of linkable registers and surveys that have been merged and made consistent (see Bakker et al., 2014). It has data on demography, education, the labour market, criminality and so forth. The criminality data in the SSD are from the HKS (Herkenningsdienstsysteem, Police Identification Service System), which covers the entire country and has been in use since 1986 to register anyone suspected of a criminal offence. The region from which first- and second-generation immigrants come is not standard information in the SSD. This study, however, was able to benefit from the findings of a project classifying the native regions and provinces of first- and second-generation Moroccans residing in the Netherlands on 1 January 2009 (Fokkema et al., 2009). The mother's origin is chosen to assess the second generation whose parents both come from Morocco. Personal identifiers are used to link the information of various registers and surveys relevant to our study. For privacy protection purposes, in order to preclude direct identification of individuals, these personal identifiers are replaced by anonymous linkage keys. Moreover, generation of the required dataset as well as the analyses are done at Statistics Netherlands, which under adequate technical and organizational measures is authorized by law to use administrative data from all government institutions for statistical and scientific purposes.

The study focuses on men of Moroccan descent in the 15-25 age group living in the Netherlands at the beginning of 2009 and on the reference date of 24 September 2010. 2,3 The research population comprises a total of 32,400 Moroccan men in the 15-25 age 
group. The study is restricted to Moroccan men because the percentage of Moroccan male suspects is more than five times higher than that of Moroccan female suspects (Jennissen and Besjes, 2012: 176-7). We restrict our study to the 15-25 age group because the percentages of suspects are much higher in this age category of the Moroccan population than in any other cohort (Jennissen and Besjes, 2012: 177).

\section{Measuring instruments}

The dependent variable is whether someone has ever been a suspect, that is, has been suspected of a criminal offence at least once before the reference date of 31 December 2010. One should bear in mind that the most recent time that a person has been a suspect may have been long before the reference date. The data pertain to people suspected of a crime by the police and not to those who have been convicted. However, more than an estimated 90 percent of youngsters suspected of a criminal offence accept a deal with the Prosecutor's Office or are sentenced and convicted by the Court at a later stage (Jennissen and Blom, 2007: 56-7). The suspected crimes vary from offences against public decency, violent offences and drug offences to traffic and property offences and violations of public order.

The independent variable we are interested in is the geographical descent of the Moroccans. In the study by Fokkema et al. (2009) referred to above, the place of birth of Moroccan residents of the Netherlands is coded into 16 administrative regions and 61 administrative provinces within these regions (see Figure 1). The native region and province in Morocco could be determined for more than 95 percent of them. For the Moroccan men aged 15-25 in our research dataset, the percentage with an unknown native region and province is 2 percent. To test Hypothesis 1a, a distinction is drawn between the provinces with Casablanca, Fes, Marrakech, Meknes, Ouarzazate, Rabat, Tangiers and Tetouan as the main cities and the rural regions. To test Hypothesis 2a, a distinction is drawn between the Rif region, that is, the provinces of Al Hoceima and Nador, and Other, that is, the other 59 provinces. Moroccans with a migration background from the urban provinces or outside the Rif constitute the reference group. It is important to note that the Rif region does not fit perfectly with the administrative provinces of Al Hoceima and Nador - the upper part of the Taounate and Taza provinces is actually part of the Rif Mountains (see Figure 2).

The following variables are used in the study to check for possible differences in the demographic composition of the various native regions: age, position in the household and level of urbanization of the current place of residence (for the distinct categories of the two latter variables, see Table 1). To test whether there is evidence of a non-linear relationship for age, its square is also included in the analysis.

Three generations are distinguished to test Hypotheses $1 \mathrm{~b}$ and $2 \mathrm{~b}$ : the first generation (the reference group), the 1.5 generation and the second generation. The 1.5 generation includes the first generation that came to the Netherlands at a young age and was largely raised and educated there. In this article, an immigration age of 12 is taken as cut-off point.

Lastly, three socioeconomic status indicators are included in the analysis to test Hypotheses 1c and 2c: educational level, disposable household income and main source of 


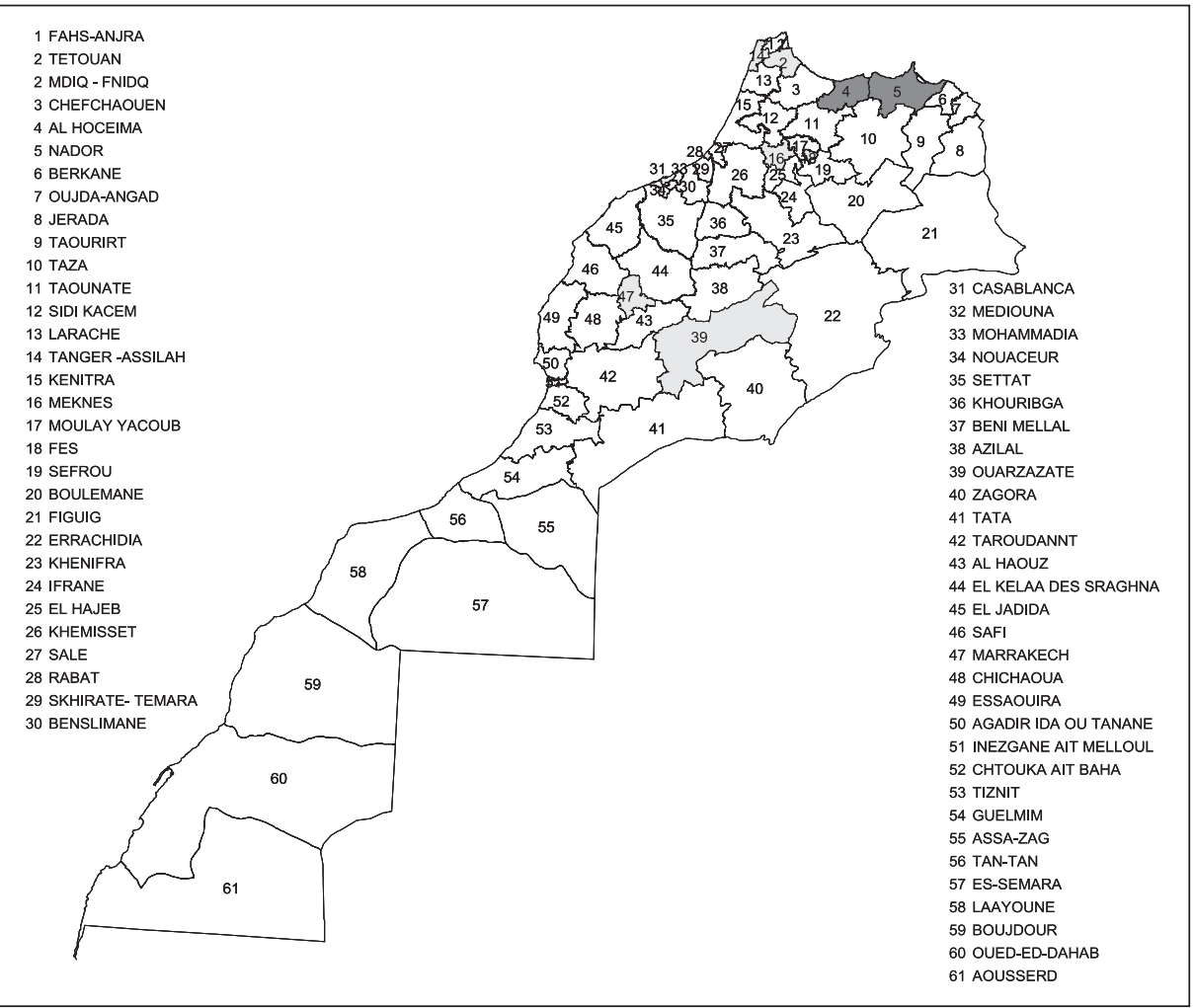

Figure I. Map of Morocco.

Note: Because there are no population figures available for Mdiq-Fnidq, this province is combined with Tetouan.

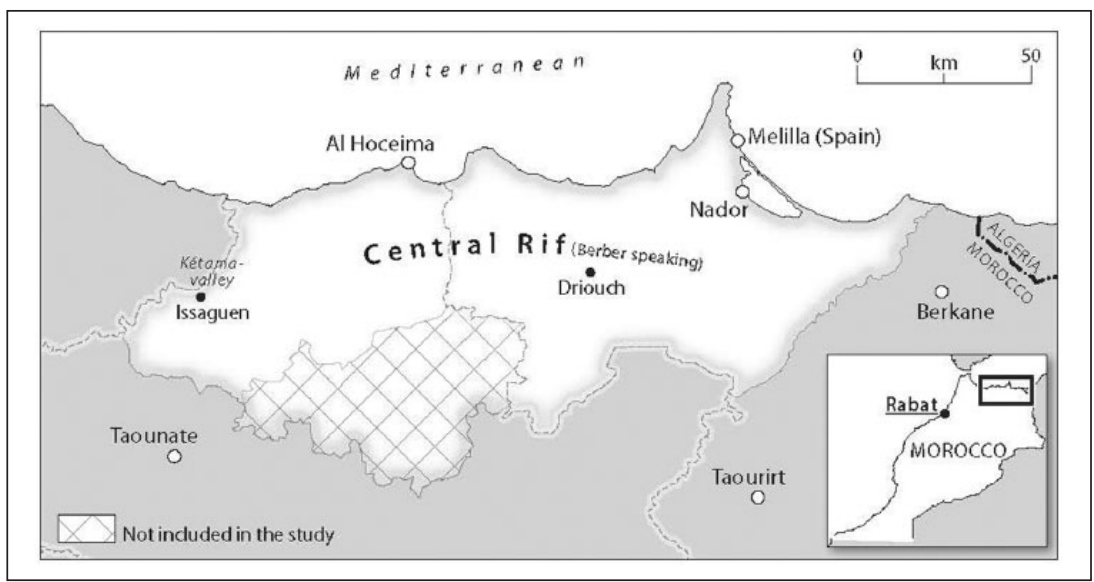

Figure 2. The Rif region. 
Table I. Descriptive statistics, I5-25-year-old Moroccan men.

Percent

Criminality

Ever a suspect

Descent, level of urbanization

Urban

Rural

Unknown

Descent, region

Rif

Al Hoceima

13.9

Nador

30.8

Non-Rif

53.2

Unknown

2.0

Demographic characteristics

Age

Household position

Child or other member (not parent) of two-parent household

52.7

Child or other member (not parent) in one-parent household

Single person

17.5

Married or cohabiting, childless

4.0

Married or cohabiting, with children

I.I

Other $^{\mathrm{a}}$

10.6

Level of urbanization of current place of residence

Very high

High

26.8

Moderate

14.0

Not very or not

6.0

Unknown

0.1

Generation

$$
\text { I }
$$

1.5

II.7

2

Socioeconomic status

Educational level

Low $^{\text {b }}$

Mediumc

55.6

High $^{d}$

17.3

Unknown

Standardized disposable household income

Unknown

0-25\% group

$25-50 \%$ group

24.4

$50-75 \%$ group

24.4

$75-100 \%$ group

24.4 
Table I. (Continued)

\begin{tabular}{|c|c|c|}
\hline & Percent & M \\
\hline \multicolumn{3}{|c|}{ Main source of income } \\
\hline Paid job & 25.2 & \\
\hline Social benefit & 7.7 & \\
\hline Pupil/student & 56.2 & \\
\hline Othere & 10.9 & \\
\hline
\end{tabular}

\section{Notes:}

a. Single parents, people in institutions and homes, and several other remaining groups.

b. Primary school, preparatory middle-level vocational school, middle-level vocational school I and first half of five- or six-year secondary school.

c. Middle-level vocational school 2-4 and second half of five- or six-year secondary school.

d. Advanced vocational school, college, first-year university examination, Bachelor's, Master's and PhD.

e. People with no income or no known source of income at the reference moment, including people receiving alimony, allowances from parents or income from capital.

income (for the distinct categories of the socioeconomic variables, see Table 1). Given the age of the research group, educational level refers to the highest grade of school attended instead of the highest diploma. The disposable household income pertains to the joint gross income of all the household members (excluding insurance premiums, taxes and paid income transfers such as alimony), and is standardized by dividing it by an equivalence factor. ${ }^{4}$ The 15-25-year-old Moroccan men's households with known annual disposable household incomes are presented in 25 percent groups of the income distribution. ${ }^{5}$

The reference date for stock data such as socioeconomic status and age is 24 September 2010. The flow data such as annual disposable household income pertain to the year 2010.

\section{Results}

Using logistic regression analysis, we calculate the net effect of Moroccan geographical descent on having ever been suspected of a criminal offence. The results are shown in Tables 2 and 3. Model 1 includes only geographical descent in the analysis. Moroccans in the 15-25 age group who come from the countryside and the Rif, or whose parents do, are more likely to have been suspected of a criminal offence than those who come from a city or from outside the Rif, or whose parents do. To exclude the possibility of these descent differences being caused by demographic composition differences, Model 2 is corrected for three demographic characteristics that prior research has shown to exert an influence on criminal conduct: age, position in the household and urbanization level of the current place of residence. There is an inverted U-shaped correlation between age and criminality in that the likelihood of having been suspected of a criminal offence at some point increases with age and then starts decreasing after the age of about 22 . Moroccans (not parents) in the 15-25 age group in a two-parent household are less likely to have been suspected of a criminal offence than those in a different type of household, with the exception of those cohabiting without children. The negative correlation between 
Table 2. Odds ratios for ever having been suspected of a criminal offence, 15-25-year-old Moroccan men: Rural versus urban background.

\begin{tabular}{|c|c|c|c|c|c|}
\hline & \multicolumn{5}{|l|}{ Model } \\
\hline & I & 2 & 3 & 4 & 5 \\
\hline \multicolumn{6}{|l|}{ Descent (ref. Urban) } \\
\hline Rural & $1.103 * * *$ & $1.138 * * *$ & $1.137 * * *$ & 1.072 & $1.101 * * *$ \\
\hline Unknown & 0.970 & 0.901 & 0.901 & $0.326 * *$ & 0.879 \\
\hline \multicolumn{6}{|l|}{ Demographic characteristics } \\
\hline Age (linear) & & $3.062^{* * *}$ & $2.980 * * *$ & $2.977 * * *$ & $3.812^{* * *}$ \\
\hline Age square & & $0.975^{* * *}$ & $0.976 * * *$ & $0.976 * * *$ & $0.972^{* * * *}$ \\
\hline \multicolumn{6}{|l|}{$\begin{array}{l}\text { Household position (ref. Child or } \\
\text { other member (not parent) of two- } \\
\text { parent household) }\end{array}$} \\
\hline $\begin{array}{l}\text { Child or other member (not parent) } \\
\text { in one-parent household }\end{array}$ & & $1.298 * * *$ & $1.298 * * *$ & $1.297 * * *$ & $1.164 * * *$ \\
\hline Single & & $1.070 *$ & $\mathrm{I} .077^{*}$ & $1.076 *$ & 1.025 \\
\hline Married or cohabiting, childless & & 1.020 & 1.025 & 1.028 & $\left.1.14\right|^{*}$ \\
\hline Married or cohabiting, with children & & $1.336 * *$ & $1.339 * *$ & $1.342^{* *}$ & $\mathrm{I} .244$ \\
\hline Other & & $1.232^{* * *}$ & $1.224 * * *$ & $1.222^{* * *}$ & $1.243 * * *$ \\
\hline \multicolumn{6}{|l|}{$\begin{array}{l}\text { Level of urbanization of current place } \\
\text { of residence (ref. Not very or not) }\end{array}$} \\
\hline Very high & & $0.833^{* * *}$ & $0.844 * * *$ & $0.845^{* * *}$ & $0.870 * *$ \\
\hline High & & $0.889 *$ & $0.890 *$ & $0.890 *$ & $0.892^{*}$ \\
\hline Moderate & & $0.877^{*}$ & $0.875^{*}$ & $0.876 *$ & $0.878 *$ \\
\hline Unknown & & 1.256 & 1.285 & 1.332 & $0.428 *$ \\
\hline \multicolumn{6}{|l|}{ Generation (ref. Ist) } \\
\hline 1.5 & & & $1.574 * * *$ & $1.487^{* * *}$ & $2.422 * * *$ \\
\hline 2 & & & $1.597 * * *$ & $1.496 * * *$ & $2.653 * * *$ \\
\hline \multicolumn{6}{|l|}{ Generation * Descent } \\
\hline I.5* Rural & & & & 1.050 & \\
\hline $2 *$ Rural & & & & 1.066 & \\
\hline I.5* Unknown & & & & $3.923 * *$ & \\
\hline $2 *$ Unknown & & & & $2.885^{*}$ & \\
\hline
\end{tabular}

\section{Socioeconomic status}

Educational level (ref. High)

Low

Medium

Unknown

Standardized disposable household income (ref. 75-100\% group)

\begin{tabular}{ll}
$0-25 \%$ group & $1.738 * * *$ \\
$25-50 \%$ group & $1.498 * * *$ \\
$50-75 \%$ group & $1.180^{* * * *}$ \\
Unknown & $2.719 * * *$ \\
\hline
\end{tabular}


Table 2. (Continued)

\begin{tabular}{llllll}
\hline & \multicolumn{1}{l}{ Model } & & & \\
\cline { 2 - 6 } & $\mathrm{I}$ & 2 & 3 & 4 & 5 \\
\hline Main source of income (ref. Paid job) & & & & & $1.514^{* * * *}$ \\
$\quad$ Social benefit & & & & & 0.935 \\
Pupil/student & & & & & $2.44 I^{* * *}$ \\
$\quad$ Other & .001 & .071 & .074 & .074 & .192 \\
Nagelkerke $R^{2}$ & & & & &
\end{tabular}

$* * * p<.001 ; * * p<.01 ; * p<.05$.

Table 3. Odds ratios for ever having been suspected of a criminal offence, 15-25-year-old Moroccan men: Rif versus non-Rif background.

\begin{tabular}{|c|c|c|c|c|c|}
\hline & \multicolumn{5}{|l|}{ Model } \\
\hline & 1 & 2 & 3 & 4 & 5 \\
\hline \multicolumn{6}{|l|}{ Descent (ref. Other) } \\
\hline Rif & $1.074 * *$ & $1.106 * * *$ & I.104*** & $1.249 *$ & $1.068^{* * * *}$ \\
\hline Unknown & 0.936 & 0.863 & 0.862 & $0.34 I^{* *}$ & 0.847 \\
\hline \multicolumn{6}{|l|}{ Demographic characteristics } \\
\hline Age (linear) & & $3.056 * * *$ & $2.975 * * *$ & $2.977 * * *$ & $3.810 * * *$ \\
\hline Age square & & $0.975 * * *$ & $0.976 * * *$ & $0.976 * * *$ & $0.972 * * *$ \\
\hline \multicolumn{6}{|l|}{$\begin{array}{l}\text { Household position (ref. Child or other } \\
\text { member (not parent) of two-parent } \\
\text { household) }\end{array}$} \\
\hline $\begin{array}{l}\text { Child or other member (not parent) } \\
\text { in one-parent household }\end{array}$ & & $1.298 * * *$ & $1.298 * * *$ & $1.296 * * *$ & $1.163 * * *$ \\
\hline Single & & $1.07 I^{*}$ & $1.078^{*}$ & $1.076 *$ & 1.026 \\
\hline Married or cohabiting, childless & & 1.020 & 1.026 & 1.029 & $1.142 *$ \\
\hline Married or cohabiting, with children & & $1.336 * *$ & $1.339 * *$ & $1.342 * *$ & 1.246 \\
\hline Other & & $1.232 * * *$ & $1.224 * * *$ & $1.222 * * *$ & $1.243^{* * *}$ \\
\hline \multicolumn{6}{|l|}{$\begin{array}{l}\text { Level of urbanization of current place of } \\
\text { residence (ref. Not very or not) }\end{array}$} \\
\hline Very high & & $0.833^{* * * *}$ & $0.845^{* * *}$ & $0.846 * * *$ & $0.87 \mid * *$ \\
\hline High & & $0.888^{*}$ & $0.889 *$ & $0.890 *$ & $0.891 *$ \\
\hline Moderate & & $0.876^{*}$ & $0.875^{*}$ & $0.876^{*}$ & $0.878^{*}$ \\
\hline Unknown & & 1.264 & 1.293 & 1.340 & $0.430 *$ \\
\hline \multicolumn{6}{|l|}{ Generation (ref. Ist) } \\
\hline 1.5 & & & $1.570 * * *$ & $1.572 * * *$ & $2.428 * * *$ \\
\hline 2 & & & $1.596 * * *$ & $1.655 * * *$ & $2.654 * * *$ \\
\hline \multicolumn{6}{|l|}{ Generation * Descent } \\
\hline I.5* Rural & & & & 0.935 & \\
\hline $2 *$ Rural & & & & 0.871 & \\
\hline I.5* Unknown & & & & $3.708^{*}$ & \\
\hline $2 *$ Unknown & & & & $2.608^{*}$ & \\
\hline
\end{tabular}


Table3. (Continued)

\section{Model}

$\begin{array}{lllll}1 & 2 & 3 & 4 & 5\end{array}$

\begin{tabular}{|c|c|c|c|c|c|}
\hline \multicolumn{6}{|c|}{ Socioeconomic status } \\
\hline \multicolumn{6}{|c|}{ Educational level (ref. High) } \\
\hline Low & & & & & $5.468 * * *$ \\
\hline Medium & & & & & $3.339 * * *$ \\
\hline Unknown & & & & & $2.242 * * *$ \\
\hline \multicolumn{6}{|c|}{$\begin{array}{l}\text { Standardized disposable household } \\
\text { income (ref. } 75-100 \% \text { group) }\end{array}$} \\
\hline $0-25 \%$ group & & & & & $1.737 * * *$ \\
\hline $25-50 \%$ group & & & & & $1.496 * * *$ \\
\hline $50-75 \%$ group & & & & & $1.179 * * *$ \\
\hline Unknown & & & & & $2.717^{* * *}$ \\
\hline \multicolumn{6}{|c|}{ Main source of income (ref. Paid job) } \\
\hline Social benefit & & & & & $1.514 * * *$ \\
\hline Pupil/student & & & & & 0.935 \\
\hline Other & & & & & $2.439 * * *$ \\
\hline Nagelkerke $R^{2}$ & .000 & .071 & .074 & .074 & .192 \\
\hline
\end{tabular}

$* * * p<.001 ; * * p<.01 ; *_{p}<.05$.

criminality and urbanization level of the current place of residence is somewhat striking. The most important finding in Model 2, however, is that, after this correction, the descent differences are even slightly greater. Hypotheses $1 \mathrm{a}$ and $2 \mathrm{a}$ are thus confirmed. Crime rates in the Netherlands are higher among Moroccans who come from the countryside and the Rif, or whose parents do, than among those who come from the urban provinces in Morocco and from outside the Rif, or whose parents do.

The influence of descent on criminality should be put into the proper perspective. Differences in geographical descent may be significant but they are small. After controlling for the three demographic characteristics, the likelihood of having been suspected of a criminal offence is 1.138 greater for 15-25-year-old Moroccans with a rural background and 1.106 greater for those with roots in the Rif. This limited influence of geographical descent on the likelihood of having been suspected of a criminal offence also manifests itself in the low-percentage variance explained by this variable, that is, the explained variance is no more than 0.1 percent (see Model 1). Because of the large size of the research population, this limited effect is nonetheless significant.

In Model 3, generation is added as a main effect and in Model 4, to test Hypotheses $1 \mathrm{~b}$ and $2 \mathrm{~b}$, also as an interaction effect with geographical descent. There is a significant difference between the first generation and the 1.5 and second generations. Young men who were born in the Netherlands or came to live there before they were 12 have a substantially greater chance of having been suspected of a criminal offence than those who spent their entire youth in Morocco. Adding the generation increases the explained variance by 0.3 percentage points. The generation difference is unrelated to geographical descent though; none of the interaction effects are significant. Hypotheses $1 \mathrm{~b}$ and $2 \mathrm{~b}$ thus 
fail to be confirmed. Regardless of the generation, Moroccans from the countryside and the Rif are somewhat more likely to have been suspected of a criminal offence.

To test Hypotheses 1c and 2c, that is, that geographical descent differences manifest themselves in socioeconomic differences in the Netherlands, several socioeconomic characteristics were added to the last model. Socioeconomic position is an extremely important predictor of having ever been suspected of a criminal offence, as is witnessed by the sharp rise of 12 percentage points in the explained part of the variance. The higher the educational, income and employment levels, the lower the likelihood of having been suspected of a criminal offence. Geographical descent differences are smaller after correcting for socioeconomic differences, though they remain significant. Hence Hypotheses 1c and 2c fail to be confirmed, and the fact that Moroccans with a rural and Rif background are more likely to have been suspected of a criminal offence is not related to a socioeconomically disadvantaged position in the Netherlands.

As noted in the research design, the provinces of Al Hoceima and Nador do not include all of the Rif region. An extra analysis has been added to also compare the two provinces to the south of the Rif - Taounate and Taza - to provinces elsewhere in Morocco. The analyses show that Moroccans who come from these provinces, or whose parents do, are especially likely to have been suspected of a criminal offence (results not presented). Here too the effects are significant yet small. A second supplementary analysis compares the provinces of Al Hoceima and Nador with the other provinces. No significant difference emerges as to a greater likelihood of having been suspected of a criminal offence (results not presented).

\section{Conclusion}

The aim of this study is to address an important question in the migration sociology of criminality. Unlike the first immigrant generation, the second generation is often characterized by high crime rates. The 1.5 generation occupies a position in the middle. Is the cause of the problem the present socioeconomic and cultural position of the immigrant group in the host country, or does it have more to do with conditions in the native country? Without further argumentation, migration sociologists generally choose the first option. Many scholars of crime among immigrants in the Netherlands have chosen the second option.

Moroccan criminality in the Netherlands gives us an opportunity to test the second option. Statistics Netherlands has data on the demographic and socioeconomic characteristics, suspected crimes and regional descent of first-generation Moroccans and their children in the Netherlands. This enables us to examine the extent to which young Moroccan men's likelihood of having been suspected of a criminal offence varies in accordance with their regional descent or that of their parents. In this contribution we have tested the often-made assumptions in the Netherlands that a rural background of the immigrant group and the specific regional background of the Rif area account for the high crime rates of 1.5- and second-generation young men.

The analyses show differences in crime rates by regional origin: immigrants from rural Morocco are more likely to have been suspected of a crime offence in the Netherlands, and so are immigrants from the formerly neglected and politically rebellious Rif Mountains region. Statistical significance, however, is not equivalent to 
scientific importance. The explanatory power of the regional difference is no higher than 0.1 percent, which is far less than one might expect based on the scholarly and policyrelated literature. That a significant correlation between regional descent and criminality is nonetheless observed has to do with the large size of the research population.

Socioeconomic status in the Netherlands exerts a considerably greater explanatory power, and there is only partial evidence that regional descent differences in Morocco manifest themselves in current socioeconomic differences. Unemployment, a low educational level and a low income are much better predictors than geographical descent of having ever been suspected of a criminal offence. The findings encourage us to seek the causes of Moroccan criminality in the Netherlands rather than in Morocco. There is also a difference between the criminality of the 1.5 generation and the first generation: regardless of their regional descent, children who arrived in the Netherlands at an early age are clearly more likely to have been suspected of a criminal offence than children who spent their entire youth in Morocco.

The conclusion is that, if we take a closer look, Moroccan criminality is a general phenomenon in the Netherlands and not the result of the rural or Rif background of many immigrants. Considering the expectation aroused in the literature about the regional background of Moroccan criminality in the Netherlands, this is a rather unexpected conclusion. It can perhaps be explained in part by the limitations of the dataset. We lack access to data on internal migration that might have preceded emigration to Europe. We do not know how many 'rural urbanites', as Van den Berg-Eldering (1978) calls them, are included in the group we categorize here as rural. This limitation is important, because male migrants sometimes deliberately had their families get used to life in Moroccan cities so the cultural transition would not be too extreme. The result might also have been different had the correlation between regional descent and criminality been examined at a lower aggregation level. After all, a high crime rate in a region as a whole can be based upon a criminal tradition of one or more places. Lastly, we should also note the risk of a false causal interpretation of our research results if having a job and an education considerably reduce the risk of joining the criminal path. It is also possible that the crime rate among young men is so high that, in itself, it is a reason to not qualify for a job or education.

Despite these limitations, the present study demonstrates that, with respect to the assumption about the immigrant-crime nexus, here again there is no reason to attach too much significance to the possibly criminogenic background of where immigrants come from and their culture. In this case, we have tested the hypotheses against regional differences in one country. Up to now, immigrant crime rates have been compared only between native countries, and this leads to comparability problems. We focused on regional differentiation within one country, so this methodological drawback plays much less of a role. For the time being, we concur with Solivetti (2010), who concludes on the grounds of a comparison between various immigrant groups in different immigration countries that the features of the host societies, more than the features of the native countries, explain more about criminality within ethnic groups.

\section{Acknowledgements}

We would like to express our sincerest thanks to Frank Linder and Gregory Besjes (Statistics Netherlands) for conducting the analyses and providing the tables. 


\section{Funding}

The author(s) received no financial support for the research, authorship, and/or publication of this article.

\section{Notes}

1. In her biting criticism of Whyte's Boston ethnography, Boelen (1992), who had lived in southern Italy, writes that second-generation Italian boys' group behaviour was similar to what she had observed in Campania.

2. When referring to men of Moroccan descent in this article, we mean men born in Morocco with at least one parent also born abroad (the first generation) as well as men born in the Netherlands but whose mother was born in Morocco or, if the mother was born in the Netherlands, whose father was born in Morocco (the second generation). For the sake of readability and conciseness, the research group is regularly referred to according to the descent classification, that is, Moroccan men, Moroccans or Moroccan. This is always a definition of descent and not of nationality.

3. The selection date of 24 September 2010 is also the reference date for the demographic and socioeconomic features (stock data) of the research target group. The criminality data are of a somewhat later date, that is, 31 December 2010. The additional requirement that the members of the group in question also had to have been living in the Netherlands at the beginning of 2009 has to do with the fact that we know the native region and province for most of them.

4. The equivalence factor reflects the scale advantages that result from keeping a joint household. Use is made of the Statistics Netherlands equivalence scale, with a single-person household taken as the standard household with factor 1. For each following person above the age of 18 , the equivalence scale adds a factor of 0.37 . Depending on the ranking in the household, this is an added factor of $0.15-0.33$ for children below the age of 18 . A single person with an income of $€ 10,000$ would thus be at the same prosperity level as a childless couple with an income of $€ 13,700$ (standardized as $€ 10,000$ ).

5. The cut-offs of the 25 percent groups of the standardized annual disposable household incomes are: $€ 11,877, € 15,209$ and $€ 20,135$.

\section{References}

Aronowitz AA (2002) Assimilation, acculturation and juvenile delinquency among secondgeneration Turkish youths in Berlin. In: Freilich JD, Newman G, Shoham SG and Addad M (eds) Migration, Culture Conflict and Crime. Dartmouth: Ashgate, 233-260.

Bakker BFM, Van Rooijen J and Van Toor L (2014) The system of social statistical datasets of Statistics Netherlands: An integral approach to the production of register-based social statistics. Statistical Journal of the International Association for Official Statistics 30: 411-424.

Blokland AAJ, Grimbergen K, Bernasco W and Nieuwbeerta P (2010) Criminaliteit en etniciteit. Criminele carrières van autochtone en allochtone jongeren uit het geboortecohort 1984 . Tijdschrift voor Criminologie 52(2): 122-152.

Boelen M (1992) Cornerville revisited. Journal of Contemporary Ethnography 21(1): 11-51.

Bouras N (2012) Het land van herkomst. Perspectieven op verbondenheid met Marokko, 19602010. Hilversum: Verloren.

Bovenkerk F (2014) Marokkaan in Europa, crimineel in Nederland. Een vergelijkende studie. The Hague: Boom/Lemma.

Brons D, Hilhorst N and Willemsen F (2008) Het kennisfundament t.b.v. de aanpak van criminele Marokkaanse jongeren. WODC Cahier 2008-4. The Hague: Ministry of Justice. 
Bucerius SM and Tonry M (eds) (2014) The Oxford Handbook of Ethnicity, Crime, and Immigration. Oxford: Oxford University Press.

Cankaya S (2012) De controle van marsmannetjes en ander schorriemorrie. Het beslissingsproces tijdens proactief politiewerk. The Hague: Boom/Lemma.

De Mas P (1987) L'évolution disparate des marges rurales marocaines: Les cas du Rif et du Sous. Plaidoyer pour une recherche scientifique adaptée au monde rural marocain. Bulletin Economique et Social du Maroc 159/160/161: 53-62.

De Mas P (2001) De poreuze noordkust van Marokko. Migratie, smokkel en hasj. Justitiële Verkenningen 27(5): 87-98.

Eisenstadt SN (1954) The Absorption of Immigrants: A Comparative Study Based Mainly on the Jewish Community in Palestine and the State of Israel. London: Routledge \& Kegan Paul.

Eldering L (1995) Child rearing in bicultural settings: A culture-ecological approach. Psychology in Developing Societies. A Journal 7(2): 133-153.

Ferracuti F (1968) European migration and crime. Collected Studies in Criminological Research 3: 9-76.

Fokkema T, Harmsen C and Nicolaas H (2009) Herkomst en vestiging van de eerste generatie Marokkanen in Nederland. Bevolkingstrends 3: 51-56.

Hart DM (2000) Tribe and Society in Rural Morocco. London: Frank Cass.

Jennissen R and Besjes G (2012) Geregistreerde criminaliteit. In: Jaarrapport integratie 2012. Statistics Netherlands, 173-192.

Jennissen R and Blom M (2007) Allochtone en autochtone verdachten van verschillende delicttypen nader bekeken. Cahier 2007-4. Voorburg/The Hague: Statistics Netherlands/Research and Documentation Centre of the Ministry of Justice.

Junger M (1990) Delinquency and Ethnicity. An Investigation on Social Factors Relating to Delinquency among Moroccan, Turkish, Surinamese and Dutch Boys. Deventer/Boston: Kluwer.

Junger-Tas J (1997) Ethnic minorities and criminal justice in the Netherlands. In: Tonry M (ed.) Ethnicity, Crime, and Immigration. Comparative and Cross-National Perspectives. Chicago/ London: University of Chicago Press, 257-311.

Junger-Tas J (2001) Ethnic minorities, social integration and crime. European Journal on Criminal Policy and Research 9(1): 4-28.

Loozen S, De Valk H and Wobma E (2012) Demografie. In: Gijsberts M, Huijnk W and Dagevos J (eds) Jaarrapport integratie 2011. The Hague: Sociaal en Cultureel Planbureau, 33-55.

Marshall-Haen I (ed.) (1997) Minorities, Migrants, and Crime. Thousand Oaks, CA: Sage.

Mears DP (2001) The immigration-crime nexus: Toward an analytic framework for assessing and guiding theory, research, and policy. Sociological Perspectives 44(1): 1-19.

Merton RK (1949) Social Theory and Social Structure. Glencoe, IL: The Free Press.

Park RE, Burgess EW and McKenzie RD (1967) The City. Chicago: University of Chicago Press (original 1925).

Pels T and De Haan M (2007) Socialization practices of Moroccan families after migration: A reconstruction in an acculturative arena. Young 15(1): 71-89.

Rumbaut R (2004) Ages, life stages, and generational cohorts: Decomposing the immigrant first and second generations in the United States. International Migration Review 38(3): $1160-1205$.

Sampson RJ (2008) Rethinking crime and immigration. Contexts 7: 28-33.

Sellin T (1938) Culture Conflict and Crime. New York: Social Science Research Council.

Shaw CR and McKay HD (1942) Juvenile Delinquency and Urban Areas: A Study of Rates of Delinquents in Relation to Differential Characteristics of Local Communities in American Cities. Chicago: University of Chicago Press. 
Shoham S (1962) The application of the culture-conflict hypothesis to the criminality of immigrants in Israel. Journal of Criminal Law and Criminology 53: 206-214.

Simes JT and Waters MC (2014) The politics of immigration and crime. In: Bucerius SM and Tonry M (eds) The Oxford Handbook of Ethnicity, Crime, and Immigration. Oxford: Oxford University Press, 457-483.

Solivetti LM (2010) Immigration, Social Integration and Crime. A Cross-National Approach. Abingdon: Routledge.

Sutherland EH (1939) Principles of Criminology. Chicago: JB Lippencott.

Svensson JS and Saharso S (2014) Proactive policing and equal treatment of ethnic-minority youths. Policing and Society 25(4): 393-408.

Thomas PM (2011) Theoretical articulation on immigration and crime. Homicide Studies 15(4): 382-403.

Tonry M (ed.) (1997) Ethnicity, Crime, and Immigration. Comparative and Cross-National Perspectives. Chicago/London: University of Chicago Press.

Van Amersfoort JMM (1982) Immigration and the Formation of Minority Groups: The Dutch Experience, 1945-1975. Cambridge: Cambridge University Press.

Van den Berg-Eldering L (1978) Marokkaanse gezinnen in Nederland. Alphen a/d Rijn: Samsom.

Van Gemert F (1998) Ieder voor zich. Kansen, cultuur en criminaliteit van Marokkaanse jongens. Amsterdam: Het Spinhuis.

Van Noije L and Kessels R (2012) Verdachten, slachtoffers en onveiligheidsgevoelens. In: Gijsberts M, Huijnk W and Dagevos J (eds) Jaarrapport integratie 2011. The Hague: Sociaal en Cultureel Planbureau, 203-226.

Waters T (1999) Crime \& Immigrant Youth. Thousand Oaks, CA: Sage.

Werdmölder H (1997) A Generation Adrift. An Ethnography of a Criminal Moroccan Gang in the Netherlands. London: Kluwer Law.

Whyte WF (1943) Street Corner Society. The Social Structure of an Italian Slum. Chicago: Chicago University Press.

Yeager MG (1996) Immigrants and Criminality: A Meta Survey. Ottawa: Government of Canada, Ministry of Citizenship and Immigration. 